Ciência Florestal, Santa Maria, v. 24, n. 1, p. 127-135, jan.-mar., 2014

ISSN 0103-9954

\title{
O EFEITO DA ÁGUA RESIDUÁRIA DA SUINOCULTURA NO DESENVOLVIMENTO E QUALIDADE DE MUDAS DE Eucalyptus urophylla
}

\author{
THE EFFECT OF SWINE WASTEWATER IN THE DEVELOPMENT AND QUALITY OF SEEDLING \\ OF Eucalyptus urophylla
}

\author{
Raquel Oliveira Batista ${ }^{1}$ Mauro Aparecido Martinez ${ }^{2}$ Haroldo Nogueira de Paiva ${ }^{3}$ \\ Rafael Oliveira Batista ${ }^{4}$ Paulo Roberto Cecon ${ }^{5}$
}

\begin{abstract}
RESUMO
Este trabalho teve como objetivo avaliar o efeito de diferentes proporções de ARS (Água Residuária da Suinocultura) e duas idades das mudas de Eucalyptus urophylla na sua qualidade morfológica. O experimento foi instalado na Área Experimental de Hidráulica, Irrigação e Drenagem do Departamento de Engenharia Agrícola da Universidade Federal de Viçosa (UFV), em Viçosa, MG, dentro de casa de vegetação. $\mathrm{O}$ experimento foi composto por 10 tratamentos em um esquema fatorial 5 x 2 (5 proporções de ARS complementadas com adubação nitrogenada de cobertura e 2 idades das mudas), com número de repetições diferentes, o delineamento estatístico utilizado foi o de blocos casualizados. Para acompanhar o crescimento das mudas da espécie estudada foram avaliadas, aos 75 e 90 dias após a semeadura, as seguintes características morfológicas: altura da parte aérea $(\mathrm{H})$, diâmetro do coleto (DC), massa seca da parte aérea (MSPA), massa seca da raiz (MSR), massa seca total (MST), relação da altura da parte aérea/diâmetro do coleto (H/DC), relação da massa seca da parte aérea/massa seca da raiz (MSPA/MSR) e o índice de qualidade de Dickson (IQD). Os resultados obtidos permitiram concluir que a proporção correspondente a $50 \%$ de ARS é a que resulta em melhores características morfológicas das mudas de eucalipto. As mudas apresentaram-se aptas ao plantio no campo somente aos 90 dias após a semeadura.
\end{abstract}

Palavras-chave: fertirrigação; eucalipto; qualidade das mudas.

\section{ABSTRACT}

This study aimed to evaluate the effect of different proportions of ARS (Swine Wastewater) and two ages of seedlings of Eucalyptus urophylla in their morphological quality. The experiment was conducted at the Experimental Hydraulics, Irrigation and Drainage Department of Agricultural Engineering, Federal University of Viçosa (UFV), in Viçosa, Minas Gerais state, in a greenhouse. The experiment consisted of 10 treatments in a factorial $5 \times 2$ (5 proportions of ARS supplemented with nitrogen fertilization and seedling age 2) with different number of repetitions, and the experimental design was a randomized block. To track the growth of seedlings of the species studied were evaluated at 75 and 90 days after sowing, the following morphological characteristics: height of shoot $(\mathrm{H})$, stem diameter $(\mathrm{CD})$, shoot dry mass (SDM), root dry mass (RDM), total dry matter (TDM), seedling height raltionship/collar diameter (H/CD), shoot dray mass ratio/root dry mass (SDM/MSR) and Dickson quality index (IQD). The results showed that the proportion of $50 \%$ of ARS is the one which results in the best morphological characteristics of eucalyptus seedlings. The seedlings showed the planting in the field only 90 days after sowing. Keywords: fertirrigation; Eucalyptus; quality seedlings.

1 Engenheira Agrônoma, Msc., Doutoranda do Programa de Pós-Graduação em Ciência do Solo, Universidade Federal de Lavras, Caixa Postal 3037, CEP 37200-000, Lavras (MG), Brasil. batista.raqueloliveira@gmail.com

2 Engenheiro Agrônomo, Dr., Professor Titular do Departamento de Engenharia Agrícola, Universidade Federal de Viçosa, Av. Peter Henry Rolfs, s/n, CEP 36570-000, Viçosa (MG), Brasil. mmauro@ufv.br

3 Engenheiro Florestal, Dr., Professor Associado do Departamento de Engenharia Florestal, Universidade Federal de Viçosa, Av. Peter Henry Rolfs, s/n, CEP 36570-000, Viçosa (MG), Brasil. hnpaiva@ufv.br

4 Engenheiro Agrícola, Dr., Professor Adjunto do Departamento de Ciências Ambientais, Universidade Federal Rural do Semi-Árido, Av. Francisco Mota, 572, Campus Leste, CEP 59625-900, Mossoró (RN), Brasil. rafaelbatista@ufersa.edu.br

5 Engenheiro Agrônomo, Dr., Professor Associado do Departamento de Estatística, Universidade Federal de Viçosa, Av. Peter Henry Rolfs, s/n, CEP 36570-000, Viçosa (MG), Brasil. cecon@ufv.br

Recebido para publicação em 8/02/2011 e aceito em 10/09/2012 


\section{INTRODUÇÃO}

A suinocultura é um setor gerador de grandes quantidades de águas residuárias. Segundo Matos (2007), pode-se considerar que a quantidade de águas residuárias produzidas nesta atividade gire em torno de 5 a $10 \mathrm{~L} \mathrm{suíno}^{-1} \mathrm{~d}^{-1}$. O destino final desse dejeto líquido é uma preocupação ambiental, uma vez que este, se manejado de forma inadequada, pode provocar sérios impactos ao meio ambiente. Uma das alternativas de reciclagem desse dejeto é o uso como fertilizante, pois os nutrientes nele contidos, após mineralizados, são disponibilizados à absorção pelas plantas. No entanto, é preciso aperfeiçoar técnicas de tratamento e manejo desses dejetos para que isso possa se tornar uma prática viável.

Os dejetos de suínos contêm matéria orgânica, nitrogênio, fósforo, potássio, cálcio, sódio, magnésio, manganês, ferro, zinco, cobre e outros elementos incluídos nas dietas e na sanidade dos animais (DIESEL et al., 2002). Em razão disso, o uso de dejetos de suínos no solo pode causar impactos ambientais positivos e, ou, negativos no sistema solo-planta relacionados a alterações físicas, químicas e biológicas.

A reciclagem dos nutrientes contidos na água residuária da suinocultura como fertilizante na produção de mudas de eucalipto pode se tornar uma alternativa promissora para destinação deste dejeto, uma vez que esta cultura possui uma importância expressiva no setor florestal brasileiro. A importância do gênero Eucalyptus é atribuída ao fato da existência de mais de 600 espécies, das quais é possível obter produtos para diversas finalidades, tais como madeira para carvão, celulose e papel, indústria moveleira, extração de óleos essenciais, mourões de cerca, dormentes, postes, dentre outras (MORA e GARCIA, 2000).

Pelissari et al. (2009) relataram que a fertirrigação com a ARS pode antecipar a produção de mudas de Eucalyptus de 90 dias para 60 dias, aproximadamente, nas condições em que foi conduzido o experimento em Santa Tereza do OestePR. Outras águas residuárias também apresentaram bons resultados quando utilizadas no setor florestal, tais como a aplicação no solo do efluente tratado de fábrica de celulose kraft branqueada, por meio da fertirrigação de eucalipto (REZENDE, 2003), e a utilização da água residuária proveniente de um sistema biológico de tratamento de esgotos domésticos na fertirrigação de viveiros para produção de Eucalyptus grandis (AUGUSTO et al., 2007).
Com base nessas informações, o objetivo desse trabalho foi avaliar o efeito de diferentes proporções de água residuária da suinocultura (ARS) e duas idades das mudas de Eucalyptus urophylla na sua qualidade morfológica.

\section{MATERIAL E MÉTODO}

No presente trabalho, as atividades de caráter experimental foram realizadas em casa de vegetação com cobertura plástica, cortinas laterais e piso constituído por brita, nas dependências da Área Experimental de Hidráulica, Irrigação e Drenagem do Departamento de Engenharia Agrícola da Universidade Federal de Viçosa (UFV), em Viçosa, MG. As de caráter analítico foram realizadas nos Laboratórios de Qualidade da Água do Departamento de Engenharia Agrícola da UFV, de Matéria Orgânica e Resíduos e de Espectrofotometria Atômica, ambos pertencentes ao Departamento de Solos da UFV. Essas atividades foram realizadas durante o período de março a junho de 2009.

A água residuária da suinocultura (ARS) utilizada no experimento foi proveniente do Setor de Suinocultura do Departamento de Zootecnia da UFV, de onde foi conduzida até um tanque de armazenamento com dimensões de 8,4 x 14,0 x 1,8 m, localizado na Área Experimental de Hidráulica, Irrigação e Drenagem do Departamento de Engenharia Agrícola.

Neste local, a ARS passou pelos tratamentos preliminar e primário. O tratamento preliminar teve o objetivo de remover sólidos grosseiros, óleos e graxas a partir da utilização de uma peneira constituída de tela de aço inox, com abertura de $47 \mu \mathrm{m}$ (diâmetro de fio: $36 \mu \mathrm{m}$, malha de 300 meshes e área aberta de 34\%), proposta por Batista (2007). $\mathrm{Na}$ caracterização da ARS, coletaram-se, aleatoriamente, seis amostras nos galões-reservatório para realização de análises químicas. Os resultados dessas análises encontram-se na Tabela 1 .

As concentrações de nitrogênio total (Ntotal) foram determinadas pelo método Kjeldahl, do fósforo total (Ptotal) e do enxofre por espectrofotometria, do potássio $\left(\mathrm{K}^{+}\right)$e do sódio $\left(\mathrm{Na}^{+}\right)$por fotometria de chama. As concentrações de cálcio $\left(\mathrm{Ca}^{2+}\right)$, magnésio $\left(\mathrm{Mg}^{2+}\right)$, ferro $\left(\mathrm{Fe}^{2+}\right)$, cobre $\left(\mathrm{Cu}^{2+}\right)$, zinco $\left(\mathrm{Zn}^{2+}\right)$ e manganês $\left(\mathrm{Mn}^{2+}\right)$ foram determinadas por espectrofotometria de absorção atômica.

A dose de aplicação da ARS foi definida baseando-se na concentração do nitrogênio, por ser 
TABELA 1: Caracterização química da água residuária da suinocultura utilizada na adubação das mudas de Eucalyptus urophylla.

TABLE 1: Chemical characterization of swine wastewater used in the fertilization of Eucalyptus urophylla seedlings.

\begin{tabular}{cccc}
\hline & & \multicolumn{2}{c}{ Valores } \\
\cline { 3 - 4 } Características & Unidade & Variação & Média \\
\hline $\begin{array}{c}\text { Nitrogênio } \\
\text { (Ntotal) }\end{array}$ & $\left(\mathrm{mg} \mathrm{L}^{-1}\right)$ & $339,71-498,92$ & 403,61 \\
$\begin{array}{c}\text { Fósforo } \\
\text { (Ptotal) }\end{array}$ & $\left(\mathrm{mg} \mathrm{L}^{-1}\right)$ & $62,24-97,85$ & 75,93 \\
Potássio & & & \\
(Ktotal) & $\left(\mathrm{mg} \mathrm{L}^{-1}\right)$ & $105,81-175,87$ & 133,07 \\
Enxofre $(\mathrm{S})$ & $\left(\mathrm{mg} \mathrm{L}^{-1}\right)$ & $10,00-14,40$ & 12,77 \\
Cálcio $(\mathrm{Ca})$ & $\left(\mathrm{mg} \mathrm{L}^{-1}\right)$ & $51,53-78,33$ & 57,33 \\
Magnésio & $\left(\mathrm{mg} \mathrm{L}^{-1}\right)$ & $19,90-35,38$ & 28,32 \\
$\quad(\mathrm{Mg})$ & & $7,54-15,20$ & 10,33 \\
Ferro $(\mathrm{Fe})$ & $\left(\mathrm{mg} \mathrm{L}^{-1}\right)$ & $0,13-0,55$ & 0,39 \\
Cobre $(\mathrm{Cu})$ & $\left(\mathrm{mg} \mathrm{L}^{-1}\right)$ & $0,12-2,10$ & 1,54 \\
Zinco $(\mathrm{Zn})$ & $\left(\mathrm{mg} \mathrm{L}^{-1}\right)$ & 1,12 & \\
Manganês & $\left(\mathrm{mg} \mathrm{L}^{-1}\right)$ & $0,84-1,14$ & 0,89 \\
$\quad(\mathrm{Mn})$ & & & \\
Sódio $(\mathrm{Na})$ & $\left(\mathrm{mg} \mathrm{L}^{-1}\right)$ & $78-96,7$ & 87,8 \\
\hline
\end{tabular}

o constituinte presente em maior concentração relativa no efluente. Essa aplicação foi realizada com o auxílio de um regador, e seguiu a exigência nutricional do eucalipto quanto à adubação de cobertura com nitrogênio, conforme sugerida por Gonçalves e Poggiani (1996).

A produção das mudas foi realizada em tubetes previamente esterilizados em água quente a $80^{\circ} \mathrm{C}$ por 30 segundos (ALFENAS et al., 1999), com capacidade volumétrica de $50 \mathrm{~cm}^{3}$.

O substrato utilizado na produção das mudas foi um substrato comercial à base de casca de Pinus, ao qual se adicionou adubação de base, que se constituiu de $150 \mathrm{~g}$ de N, $300 \mathrm{~g}$ de $\mathrm{P}_{2} \mathrm{O}_{5}$ e $100 \mathrm{~g}$ de $\mathrm{K}_{2} \mathrm{O}$ para cada $\mathrm{m}^{3}$ de substrato (GONÇALVES e POGGIANI, 1996). Foram utilizados como fontes desses nutrientes o sulfato de amônio, o superfosfato simples e o cloreto de potássio, respectivamente. Anteriormente à adubação de base foram realizadas análises físicas e químicas do substrato, conforme indicadas nas Tabelas 2 e 3, respectivamente.

De acordo com a escala de valores para interpretação de características físicas e químicas de substratos usados para produção de mudas de espécies florestais no sistema de tubetes, proposta por Gonçalves e Poggiani (1996), verifica-se que os valores (Tabela 2) de massa específica global, de macroporosidade e da porosidade total, estão em níveis considerados médios, enquanto que a microporosidade encontra-se em nível adequado.

TABELA 2: Características físico-químicas do substrato à base de casca de pinus (SCP) antes da adubação de base.

TABLE 2: Physico-chemical properties of the substrate of pine bark (SCP) before the fertilizer application.

\begin{tabular}{ccccccccccc}
\hline & $\mathrm{pH}$ & $\mathrm{MO}$ & $\mathrm{MEG}^{1}$ & $\mathrm{MEP}^{2}$ & $\mathrm{MAC}^{3}$ & $\mathrm{MIC}^{3}$ & $\mathrm{PT}^{3}$ & $\mathrm{CT}$ & $\mathrm{C} / \mathrm{N}$ & $\mathrm{UT}$ \\
\hline \multirow{3}{*}{$\mathrm{SCP}$} & - & $(\%)$ & $\left(\mathrm{g} \mathrm{cm}^{-3}\right)$ & $\left(\mathrm{g} \mathrm{cm}^{-3}\right)$ & $(\%)$ & $(\%)$ & $(\%)$ & $\left(\mathrm{g} \mathrm{kg}^{-1}\right)$ & - & $(\%)$ \\
\cline { 2 - 11 } & 7,56 & 55,1 & 0,40 & 1,14 & 21,32 & 51,13 & 64,91 & 324,1 & $54 / 1$ & 25,12 \\
\hline
\end{tabular}

Em que: 1 - determinada conforme Instrução Normativa SDA n ${ }^{\circ} 17$ de 24/05/2007; 2 - segundo a metodologia proposta pela EMBRAPA (1997); 3 - metodologia proposta por Gonçalves e Poggiani (1996). *pH: potencial hidrogeniônico; MO: matéria orgânica; MEG: massa específica global; MEP: massa específica de partículas; MAC: macroporosidade; PT: porosidade total; CT: carbono total; C/N: relação carbono/nitrogênio; UT: umidade total.

TABELA 3: Concentrações de macronutrientes, micronutrientes e sódio no substrato à base de casca de pinus (SCP) antes da adubação de base.

TABLE 3: Concentrations of macronutrients, micronutrients and sodium based substrate of pine bark (SCP) before the fertilizer application.

\begin{tabular}{|c|c|c|c|c|c|c|c|c|c|c|c|}
\hline & $\mathrm{N}$ & $\mathrm{P}$ & $\mathrm{K}$ & $\mathrm{S}$ & $\mathrm{Ca}$ & $\mathrm{Mg}$ & $\mathrm{Fe}$ & $\mathrm{Cu}$ & $\mathrm{Zn}$ & $\mathrm{Mn}$ & $\mathrm{Na}$ \\
\hline & \multicolumn{6}{|c|}{$\left(\mathrm{g} \mathrm{kg}^{-1}\right)$} & \multicolumn{4}{|c|}{$\left(\mathrm{mg} \mathrm{kg}^{-1}\right)$} & $\left(\mathrm{g} \mathrm{kg}^{-1}\right)$ \\
\hline SCP & 6,1 & 10,3 & 5,2 & 3,4 & 3,3 & 0,5 & 5715 & 26,9 & 38,1 & 573,5 & 0,1 \\
\hline
\end{tabular}


A relação $\mathrm{C} / \mathrm{N}$ encontra-se acima da considerada adequada (8 a 12/1) (GONÇALVES; POGGIANI, 1996). As análises químicas do substrato (Tabela 3) indicaram concentrações consideráveis de nutrientes, com destaque para fósforo, ferro e manganês.

O desbaste foi realizado no momento em que as mudas atingiram cerca de $3 \mathrm{~cm}$ de altura (30 dias após a semeadura), deixando-se apenas uma planta por recipiente, a mais central e robusta.

As adubações nitrogenadas, tanto com a ARS quanto com o adubo mineral, foram realizadas a cada 7 dias, a partir de 10 dias após o desbaste até aos 75 dias após a germinação. Intercaladas com a adubação nitrogenada, foram feitas adubações com potássio, a cada 14 dias, totalizando em 6 e 3 aplicações, respectivamente. A recomendação utilizada foi composta por $1 \mathrm{~kg}$ de sulfato de amônio e/ou $300 \mathrm{~g}$ de cloreto de potássio em $100 \mathrm{~L}$ de água, sendo suficiente para adubação de 10.000 mudas (GONÇALVES e POGGIANI, 1996), aplicando cerca de $10 \mathrm{ml}$ para cada muda. A disponibilidade de micronutrientes para as mudas foi proveniente do substrato e da ARS.

As mudas foram irrigadas diariamente com uma lâmina média de $5 \mathrm{~mm}$, parcelada em três vezes, nos horários de 10,13 e 16 h. Esta lâmina foi aproximada da recomendada por Gruber (2006) para produção de mudas de eucalipto $(6 \mathrm{~mm})$ na região de Bofete - SP, no inverno.

As proporções de ARS forneceram às mudas, além do nitrogênio, outros nutrientes essenciais. Com isto, fez-se uma correção na adubação de cobertura quanto ao fósforo e ao potássio correspondente a $100 \%$ das suas concentrações fornecidas pela proporção $\mathrm{ARS}_{5}$. Essa adubação complementar foi realizada com fosfato de sódio e cloreto de potássio, respectivamente.

A partir dos 75 dias após a germinação foi realizada a rustificação das mudas, em que consiste no corte das adubações de cobertura e na diminuição da quantidade de água na irrigação.

$\mathrm{O}$ experimento foi instalado em esquema fatorial $5 \times 2$, composto por 10 tratamentos (5 proporções de ARS complementadas com adubação nitrogenada mineral e 2 idades das mudas) (Tabela 4). Devido às perdas de algumas repetições no final do experimento, a avaliação das mudas no substrato com as combinações das adubações $\mathrm{ARS}_{1}, \mathrm{ARS}_{4}$ e $\mathrm{ARS}_{5}$ foi composta por quatro repetições e as demais por três. O delineamento experimental adotado foi de blocos casualiza- dos, sendo a parcela constituída por 48 mudas, dos quais 30 corresponderam à área útil e 18 à bordadura.

Aos 75 e 90 dias da semeadura, foram avaliadas as seguintes características morfológicas e suas relações: altura das mudas $(\mathrm{H})$, diâmetro do coleto (DC), massa seca da parte aérea (MSPA), massa seca da raiz (MSR), massa seca total (MST), relação da altura da muda/diâmetro do coleto $(\mathrm{H} / \mathrm{DC})$, relação da massa seca da parte aérea/massa seca da raiz (MSPA/MSR) e o índice de qualidade de Dickson (IQD).

A altura das mudas foi determinada com uma régua milimetrada, medidas do nível do substrato até as pontas das últimas folhas, e o diâmetro do coleto foi determinado com um paquímetro digital. A MSPA, a MSR e a MST foram obtidas após a secagem em estufa com circulação forçada de ar sob temperatura de $65^{\circ} \mathrm{C}$ até atingirem massa constante. Para tal finalidade, separou-se a parte aérea da raiz, cortando-se no nível do coleto da planta, a seguir foram lavadas com água destilada, acondicionadas em embalagens de papel e direcionadas para a estufa. Após esta operação, o material foi resfriado em um dessecador de sílica gel, em seguida pesado em uma balança digital (precisão de $0,01 \mathrm{~g}$ ) para a determinação da massa da matéria seca.

TABELA 4: Composição dos tratamentos do experimento.

TABLE 4: Composition of the experimental treatments.

\begin{tabular}{lcc}
\hline & \multicolumn{2}{c}{ Composição } \\
\cline { 2 - 3 } Tratamentos & ARS (\%) & $\begin{array}{c}\text { Adubação } \\
\text { Nitrogenada (\%) }\end{array}$ \\
\hline ARS $_{1}-$ DAS $_{1}$ & 0 & 100 \\
ARS $_{2}-$ DAS $_{1}$ & 25 & 75 \\
ARS $_{3}-$ DAS $_{1}$ & 50 & 50 \\
ARS $_{4}-$ DAS $_{1}$ & 75 & 25 \\
ARS $_{5}-$ DAS $_{1}$ & 100 & 0 \\
ARS $_{1}-$ DAS $_{2}$ & 0 & 100 \\
ARS $_{2}-$ DAS $_{2}$ & 25 & 75 \\
ARS $_{3}-$ DAS $_{2}$ & 50 & 50 \\
ARS $_{4}-$ DAS $_{2}$ & 75 & 25 \\
ARS $_{5}-$ DAS $_{2}$ & 100 & 0 \\
\hline
\end{tabular}

Em que: DAS = dias após a semeadura. 
O índice de qualidade de Dickson (IQD) foi determinado segundo a Eq. 1 (DICKSON et al., 1960 apud CARNEIRO, 1995):

$$
I Q D=\left(\frac{M S T}{\frac{H}{D C}+\frac{M S P A}{M S R}}\right)
$$

Em que: MST: massa seca total (g); H: altura (cm); DC: diâmetro do coleto (mm); MSPA: massa seca da parte aérea (g) e MSR: massa seca da raiz (g).

Os dados das características morfológicas das mudas foram submetidos à análise de variância e as médias foram comparadas utilizando-se o teste de Tukey a 5\% de probabilidade. Esses dados fo- ram analisados estatisticamente com a utilização do software SAEG 9.1 (SAEG, 2007).

\section{RESULTADOS E DISCUSSÃO}

A análise de variância das características morfológicas encontra-se nas Tabelas 5 e 6 . A análise de variância mostrou que os fatores proporção ARS (PARS) e idade das mudas (DAS), isoladamente, foram significativos para todas as características avaliadas, exceto para o DC e a MSPA/MSR para o primeiro e a H/DC para o segundo fator. Observou-se que não houve interação significativa entre proporções de ARS e idade das mudas para nenhuma das características avaliadas.

TABELA 5: Resumo da análise de variância da altura da parte aérea (H), diâmetro do coleto (DC) e relação da altura da parte aérea/diâmetro do coleto (H/DC) de mudas de Eucalyptus urophylla.

TABLE 5: Summary of analysis of variance of shoot height (H), lap diameter (DC) and ratio of shoot height/lap diameter (H/DC) of Eucalyptus urophylla.

\begin{tabular}{lcccc}
\hline \multirow{2}{*}{ Fonte de variação } & \multirow{2}{*}{ G.L. } & \multicolumn{3}{c}{ Quadrados Médios } \\
\cline { 3 - 5 } & & $\mathrm{H}$ & $\mathrm{DC}$ & $\mathrm{H} / \mathrm{DC}$ \\
\hline Bloco & 3 & 4,9898 & 0,0029 & 1,3650 \\
Proporção ARS (PARS) & 4 & $26,2802^{* *}$ & $0,1016 \mathrm{~ns}$ & $1,4142^{*}$ \\
Idade das mudas (DAS) & 1 & $281,9461^{* *}$ & $2,9485^{* *}$ & $0,0007 \mathrm{~ns}$ \\
PARS x DAS & 4 & $16,7335 \mathrm{~ns}$ & $0,0458 \mathrm{~ns}$ & $0,2467 \mathrm{~ns}$ \\
Resíduo & 23 & 104,8740 & 0,0463 & 0,4417 \\
CV $(\%)$ & & 10,34 & 10,12 & 6,84 \\
\hline
\end{tabular}

Em que: * Significativo a $5 \%$ de probabilidade, pelo teste $\mathrm{F} ; * *$ Significativo a $1 \%$ de probabilidade, pelo teste $\mathrm{F} ; \mathrm{ns}=$ não significativo a 5\% de probabilidade; $\mathrm{GL}=$ graus liberdade; $\mathrm{CV}(\%)=$ coeficiente de variação.

TABELA 6: Resumo da análise de variância das características morfológicas das mudas de Eucalyptus urophylla: massa seca da parte aérea (MSPA), massa seca da raiz (MSR), massa seca total (MST), relação das massas secas da parte aérea e raiz (MSPA/MSR) e índice de qualidade de Dickson (IQD).

TABLE 6: Summary of analysis of variance of morphological traits of Eucalyptus urophylla: dry mass of shoot (MSPA), root dry mass (MSR), total dry matter (MST), ratio of dry mass of shoot and $\operatorname{root}(\mathrm{MSPA} / \mathrm{MSR})$ and quality index Dickson (IQD).

\begin{tabular}{lcccccc}
\hline \multirow{2}{*}{ Fonte de Variação } & \multirow{2}{*}{ G.L. } & \multicolumn{5}{c}{ Quadrados Médios } \\
\cline { 3 - 7 } & & MSPA & MSR & MST & MSPA/MSR & IQD \\
\hline Bloco & 3 & 0,0300 & 0,0039 & 0,0501 & 0,4665 & 0,0001 \\
Proporção ARS (PARS) & 4 & $0,1517^{* *}$ & $0,0052^{*}$ & $0,2099^{* *}$ & $0,6287 \mathrm{~ns}$ & $0,0006^{* *}$ \\
Idade das mudas (DAS) & 1 & $0,6165^{* *}$ & $0,0090^{*}$ & $0,7748^{* *}$ & $4,7723^{* *}$ & $0,0031^{* *}$ \\
PARS x DAS & 4 & $0,0187 \mathrm{~ns}$ & $0,0003 \mathrm{~ns}$ & $0,0238 \mathrm{~ns}$ & $0,1166 \mathrm{~ns}$ & $0,0001 \mathrm{~ns}$ \\
Resíduo & 23 & 0,0150 & 0,0012 & 0,0213 & 0,2530 & 0,0001 \\
CV (\%) & & 17,66 & 17,02 & 16,20 & 15,13 & 14,93 \\
\hline
\end{tabular}

Em que: * Significativo a $5 \%$ de probabilidade, pelo teste $\mathrm{F} ; * *$ Significativo a $1 \%$ de probabilidade, pelo teste $\mathrm{F} ; \mathrm{ns}=$ não significativo a 5\% de probabilidade; G.L. = graus liberdade; CV (\%) = coeficiente de variação. 
Na Tabela 7 são apresentados os resultados do teste de médias para as características morfológicas que foram significativas para o fator proporção de ARS no teste $\mathrm{F}$, além das médias correspondentes àquelas que não apresentaram significância estatística. As médias apresentadas para todas as características avaliadas em função das proporções de ARS foram obtidas a partir de uma média geral com os valores das duas idades das mudas, aos 75 e 90 dias. De forma geral, as características apresentaram comportamento semelhante em função das diferentes proporções de ARS.

Observa-se que a altura apresentou valor médio superior quando as plantas foram submetidas à proporção $\mathrm{ARS}_{1}$, porém, difere, estatisticamente, apenas das mudas submetidas à proporção $\mathrm{ARS}_{5}$. A ARS foi composta por $100 \%$ da adubação nitrogenada com sulfato de amônio e indicou um valor médio na altura de $22,81 \mathrm{~cm}$ (Tabela 7).

Sendo o valor mínimo de altura da muda dessa espécie para plantio no campo de $15 \mathrm{~cm}$, estabelecido por Guerreiro e Colli Junior (1984), todas as proporções de ARS se enquadraram no padrão, inclusive a $\mathrm{ARS}_{5}$ composta por $100 \%$ de ARS, a qual apresentou menor média, $17,97 \mathrm{~cm}$.

A ARS utilizada no presente trabalho proporcionou bom desenvolvimento às mudas de eucalipto com ênfase em suas alturas, tal fato também foi verificado por Pelissari et al. (2009) ao utilizarem esse dejeto líquido. Os autores relataram que a ARS produziu maior efeito positivo para altura de mudas de eucalipto. A pesquisa baseou-se na utilização deste dejeto como irrigação para produção de mudas de Eucalyptus grandis utilizando-se uma lâmina diária de $12 \mathrm{~mm}$.
A relação altura/diâmetro do coleto (H/DC) apresentou comportamento semelhante (Tabela 7) ao observado em relação à altura em função das proporções de ARS, com destaque de a maior média ter sido obtida em plantas submetidas à proporção $\mathrm{ARS}_{1}$, a qual difere apenas das obtidas nas plantas submetidas à $\mathrm{ARS}_{5}$. Observou-se, ainda, que a proporção $\mathrm{ARS}_{5}$ não diferiu das $\mathrm{ARS}_{2}, \mathrm{ARS}_{3}$ e $\mathrm{ARS}_{4}$. Tal relação exprime a qualidade das mudas em qualquer estágio de desenvolvimento, que, segundo Carneiro (1995), deve situar-se no intervalo de 5,4 a 8,1 para Pinus sp. Considerando que esse intervalo possa ser utilizado para mudas de eucalipto, no presente estudo foram observados valores médios superiores a 9,0 (Tabela 7), que, no entanto, não afetaram negativamente a qualidade das mudas, pois estas atingiram altura e diâmetro do coleto ideais para o plantio. Em pesquisas realizadas com produção de mudas de eucalipto por outros autores, também foram determinados índices mais elevados, como, por exemplo, Lopes et al. (2007) e Lopes (2008) que verificaram valores dessa relação superiores a 7,5 e próximos de 9,0, respectivamente.

A massa seca da parte aérea (MSPA), a massa seca da raiz (MSR) e a massa seca total (MST) foram maiores nas mudas pertencentes à proporção $\mathrm{ARS}_{1}$. Porém, para as características MSPA e MST avaliadas nas mudas, a proporção $\mathrm{ARS}_{1}$ apresentou diferença estatística em relação às proporções $\mathrm{ARS}_{4}$ e $\mathrm{ARS}_{5}$; e na MSR apenas à $\mathrm{ARS}_{5}$. O acúmulo de biomassa é uma característica importante relacionada ao crescimento da planta, quanto maior o valor da MST, melhor a qualidade da muda. De acordo com Koslowski et al. (1991), o crescimento inicial das plantas no campo depende de fotos-

TABELA 7: Valores médios das características morfológicas das mudas apresentadas com o uso do substrato à base de casca de pinus em função das proporções de ARS.

TABLE 7: Mean values of morphological characteristics of seedlings provided with the use of substrate pine bark according to the proportions of ARS.

\begin{tabular}{ccccccccc}
\hline $\begin{array}{c}\text { Proporções } \\
\text { de ARS }\end{array}$ & $\begin{array}{c}\mathrm{H} \\
(\mathrm{cm})\end{array}$ & DC $(\mathrm{mm})$ & H/DC & MSPA $(\mathrm{g})$ & $\begin{array}{c}\text { MSR } \\
(\mathrm{g})\end{array}$ & $\begin{array}{c}\text { MST } \\
(\mathrm{g})\end{array}$ & $\begin{array}{c}\text { MSPA/ } \\
\text { MSR }\end{array}$ & IQD \\
\hline $\mathrm{ARS}_{1}$ & $22,81 \mathrm{a}$ & 2,27 & $10,10 \mathrm{a}$ & $0,89 \mathrm{a}$ & $0,23 \mathrm{a}$ & $1,12 \mathrm{a}$ & 3,81 & $0,080 \mathrm{a}$ \\
$\mathrm{ARS}_{2}$ & $21,66 \mathrm{a}$ & 2,19 & $9,87 \mathrm{ab}$ & $0,72 \mathrm{ab}$ & $0,21 \mathrm{ab}$ & $0,94 \mathrm{ab}$ & 3,28 & $0,070 \mathrm{abc}$ \\
$\mathrm{ARS}_{3}$ & $20,62 \mathrm{ab}$ & 2,18 & $9,42 \mathrm{ab}$ & $0,70 \mathrm{abc}$ & $0,22 \mathrm{ab}$ & $0,93 \mathrm{ab}$ & 3,17 & $0,074 \mathrm{ab}$ \\
$\mathrm{ARS}_{4}$ & $19,82 \mathrm{ab}$ & 2,02 & $9,82 \mathrm{ab}$ & $0,63 \mathrm{bc}$ & $0,19 \mathrm{ab}$ & $0,82 \mathrm{bc}$ & 3,27 & $0,062 \mathrm{bc}$ \\
$\mathrm{ARS}_{5}$ & $17,97 \mathrm{~b}$ & 2,01 & $9,02 \mathrm{~b}$ & $0,51 \mathrm{c}$ & $0,17 \mathrm{~b}$ & $0,68 \mathrm{c}$ & 3,08 & $0,057 \mathrm{c}$ \\
\hline
\end{tabular}

Em que: $\mathrm{ARS}_{1}: 0 \%$ do $\mathrm{N}$ fornecido pela ARS e $100 \%$ pela adubação mineral; ARS : $25 \%$ do N fornecido pela ARS e $75 \%$ pela adubação mineral; $\mathrm{ARS}_{3}: 50 \%$ do $\mathrm{N}$ fornecido pela ARS e $50 \%$ pela adubação mineral; $\mathrm{ARS}_{4}: 75 \%$ do $\mathrm{N}$ fornecido pela ARS e $25 \%$ pela adubação mineral; $\mathrm{ARS}_{5}: 100 \%$ do N fornecido pela ARS e $0 \%$ pela adubação mineral. Médias seguidas de pelo menos uma mesma letra não diferem entre si a $5 \%$ de probabilidade pelo teste Tukey. $\mathrm{H}=$ altura da parte aérea; $\mathrm{DC}=$ diâmetro do coleto; $\mathrm{H} / \mathrm{DC}$ = relação da altura da parte aérea/diâmetro do coleto; MSPA = massa seca da parte aérea; MSR = massa seca da raiz; MST = massa seca total; MSPA/MSR = relação das massas secas da parte aérea e raiz; IQD = índice de qualidade de Dickson. 
sintatos armazenados pela muda. O maior acúmulo de fotossintatos ocorre na parte aérea da muda. Em contrapartida, quando alguns nutrientes limitam o crescimento vegetal, como o $\mathrm{N}$ e o $\mathrm{P}$, as raízes transformam-se em um forte dreno de carboidratos, causando, assim, maior limitação ao crescimento da parte aérea do que da raiz (ARAÚJO e MACHADO, 2006)

O índice de qualidade de Dickson é mencionado como bom indicador do padrão de qualidade das mudas, pois considera em seu cálculo a robustez e o equilíbrio da distribuição da biomassa (FONSECA, 2000). Hunt (1990 apud GOMES, 2001) estabelece um valor mínimo de 0,20 como bom indicador da qualidade de mudas de Pseudotsuga menziesii e Picea abies. Considerando o IQD médio encontrado, no presente ensaio, para mudas de Eucalyptus urophylla, esta referência não foi adequada para comparação, pois apresentou um intervalo de 0,057 a 0,08 (Tabela 7). O maior índice foi alcançado pelas plantas submetidas à proporção de $\mathrm{ARS}_{1}$, com uma média de 0,08 , em que se diferenciou pelo teste de Tukey a 5\% de probabilidade, das submetidas à $\mathrm{ARS}_{4}$ e $\mathrm{ARS}_{5}$. Este índice também não foi adequado para avaliar a qualidade das mudas de Eucalyptus badjensis, conforme observado por Maeda et al. (2006), pois os IQDs avaliados estão no intervalo de 0,02 a 0,09 . Porém, considerando a produção de mudas de eucalipto em tubetes com volume aproximado de $50 \mathrm{~cm}^{3}$, verificou-se, em trabalhos de outros pesquisadores, um valor médio em torno de 0,03, avaliado aos 90 dias (GOMES, 2001; BINOTTO, 2007). Valores médios de IQD superiores a 0,2 foram encontrados por Gomes (2001) em mudas de Eucalyptus grandis produzidas em tubetes maiores ( 200 e $280 \mathrm{~cm}^{3}$ ) com 120 dias de idade.

O fator proporção de ARS não foi significativo pelo teste $\mathrm{F}$ para a característica diâmetro do coleto (DC) (Tabela 7), no entanto, as plantas apresentaram valor médio superior a $2 \mathrm{~mm}$ quando sub- metidas a todas as combinações entre adubo mineral e orgânico (ARS). Este valor se enquadra no padrão mínimo para o plantio sugerido por Guerreiro e Colli Junior (1984).

O fator proporção de ARS também não foi significativo pelo teste $\mathrm{F}$ para a característica relação massa seca da parte aérea/massa seca da raiz (MSPA/ MSR), porém, as mudas correspondentes apresentaram médias superiores a 3,0. Considerando 2,0 a melhor relação entre a massa seca da parte aérea e a massa seca de raiz, conforme Brissette (1984 apud CRUZ et al., 2006), a relação mínima determinada nesta pesquisa não se ajusta. Este fato pode estar relacionado com o suprimento de $\mathrm{N}$ às mudas via ARS ou via adubo mineral, contribuindo para um melhor desenvolvimento da parte aérea em relação à raiz. No entanto, relações superiores a 2,0 também foram obtidas por Gomes (2001).

Com o intuito de verificar a possibilidade de adquirir mudas com padrões adequados ao plantio no campo em um tempo inferior a 90 dias após a semeadura, avaliaram-se todas as características em duas idades das mudas, aos 75 e aos 90 dias após a semeadura. Na Tabela 8, observam-se maiores médias para as características avaliadas aos 90 dias, exceto para H/DC, que não se diferenciou da avaliação feita aos 75 dias. Os valores considerados ideais referentes à maioria das características morfológicas foram evidenciados aos 90 dias, inclusive maior acúmulo de massa seca. Portanto, considerando-se apenas a altura aos 75 dias como uma característica de inferência sobre a qualidade de mudas, pode-se verificar a adequação ao padrão, todavia quando se analisa o diâmetro de coleto, o valor já não é indicado.

Alguns autores, com pesquisas voltadas à produção de mudas de eucalipto via semente, relataram a obtenção de mudas aptas ao plantio com um tempo inferior a 90 dias. Dentre esses pesquisadores relatam-se Barroso et al. (2000) que produziram

TABELA 8: Valores médios das características morfológicas em função da idade das mudas, aos 75 (DAS $)$ e $90\left(\mathrm{DAS}_{2}\right)$ dias após a semeadura.

TABLE 8: Mean values of morphological characteristics depending on the age of the seedlings at 75 $\left(\mathrm{DAS}_{1}\right)$ and $90\left(\mathrm{DAS}_{2}\right)$ days after sowing.

\begin{tabular}{ccccccccc}
\hline $\begin{array}{c}\text { Idade das mudas } \\
(\text { Dias })^{1}\end{array}$ & $\begin{array}{c}\mathrm{H} \\
(\mathrm{cm})\end{array}$ & $\begin{array}{c}\mathrm{DC} \\
(\mathrm{mm})\end{array}$ & $\mathrm{H} / \mathrm{DC}$ & $\begin{array}{c}\text { MSPA } \\
(\mathrm{g})\end{array}$ & $\begin{array}{c}\text { MSR } \\
(\mathrm{g})\end{array}$ & $\begin{array}{c}\text { MST } \\
(\mathrm{g})\end{array}$ & $\begin{array}{c}\text { MSPA/ } \\
\text { MSR }\end{array}$ & $\begin{array}{c}\text { IQD } \\
\text { DAS }\end{array}$ \\
\hline DAS $_{2}$ & $23,82 \mathrm{~b}^{2}$ & $1,83 \mathrm{~b}$ & $9,73 \mathrm{a}$ & $0,56 \mathrm{~b}$ & $0,19 \mathrm{~b}$ & $0,75 \mathrm{~b}$ & $2,95 \mathrm{~b}$ & $0,059 \mathrm{~b}$ \\
\hline
\end{tabular}

Em que: ${ }^{1}=$ Dias após a semeadura: $\operatorname{DAS}_{1}(75$ dias $)$ e $\operatorname{DAS}_{2}(90$ dias $) ;{ }^{2}=$ Médias seguidas pela mesma letra na coluna não diferem entre si a $1 \%$ de probabilidade pelo teste $\mathrm{F}$. $\mathrm{H}=$ altura da parte aérea; $\mathrm{DC}=$ diâmetro do coleto; $\mathrm{H} / \mathrm{DC}=$ relação da altura da parte aérea/diâmetro do coleto; MSPA = massa seca da parte aérea; MSR = massa seca da raiz; MST = massa seca total; MSPA/MSR = relação das massas secas da parte aérea e raiz; IQD = índice de qualidade de Dickson. 
mudas de Eucalyptus camaldulensis e Eucalyptus urophylla em blocos prensados, obtendo valores de altura e diâmetro do coleto que permitissem a efetuação do plantio aos 75 dias; e Pelissari et al. (2009) que afirmaram que a ARS propiciou a obtenção de uma relação altura/diâmetro que pode antecipar a produção de mudas de Eucalyptus de 90 para 60 dias.

Os valores médios das características morfológicas apresentados pelas mudas de eucalipto em função das diferentes proporções de ARS alcançaram os padrões mínimos estabelecidos para seu plantio no campo. Contudo, a proporção de $50 \%$ de ARS $\left(\mathrm{ARS}_{3}\right.$ ) seria a mais indicada, visto que, ao realizar testes de contrastes entre as médias, todas as médias das características morfológicas avaliadas nas mudas foram estatisticamente iguais às obtidas com a proporção $\mathrm{ARS}_{1}$. A época mais indicada para o plantio das mudas no campo é aos 90 dias, pois as mudas alcançaram os padrões mínimos exigidos, principalmente, na altura e no diâmetro do coleto.

\section{CONCLUSÕES}

A proporção correspondente a 50\% de ARS é a que resulta em melhores características morfológicas das mudas de eucalipto, com um bom aproveitamento do dejeto líquido;

As características morfológicas consideradas adequadas ao plantio são alcançadas aos 90 dias após a semeadura.

\section{AGRADECIMENTOS}

À Coordenação de Aperfeiçoamento de Pessoal de Nível Superior (CAPES) pelo apoio financeiro com a concessão da bolsa de pesquisa; e a todos que colaboraram na realização das atividades no decorrer do experimento.

\section{REFERÊNCIAS BIBLIOGRÁFICAS}

ALFENAS, A. C. et al. Mofo-cinzento, causado por Botrytis cinerea (Persoon ex Fries) em estacas e microestacas de Eucalyptus sp., resistência a benomil e erradicação de inóculo do patógeno com água quente. Revista Árvore, Viçosa. v. 4, n. 23, p. 497-500, 1999.

ARAÚJO, A. P.; MACHADO, C. T. de T. Fósforo. In: FERNANDES, M. S. Nutrição mineral de plantas. Viçosa-MG: Sociedade Brasileira de Ciência do Solo, 2006. Cap. 10, p. 253-280.
AUGUSTO, D. C. C. et al. Utilização de águas residuárias provenientes do tratamento biológico de esgotos domésticos na produção de mudas de Eucalyptus grandis Hill. Ex. Maiden. Revista Árvore, Viçosa, v. 31, n. 04, p. 8, 2007.

BARROSO, D. G.; CARNEIRO, J. G.de A.; LELES, P. S. S. Qualidade de mudas de Eucalyptus camaldulensis e Eucalyptus urophylla produzidas em tubetes e em blocos prensados, com diferentes substratos. Floresta e Ambiente, v. 7, n. 1, p.238 250, 2000.

BATISTA, R. O. Desempenho de sistema de irrigação por gotejamento utilizado na aplicação de água residuária de suinocultura. 2007. 146 f. Tese (Doutorado em Engenharia Agrícola) Universidade Federal de Viçosa. Viçosa, 2007.

BINOTTO, A. F. Relação entre variáveis de crescimento e o Índice de Qualidade de Dickson em mudas de Eucalyptus grandis W. Hill ex Maid e Pinus elliottii var. elliottii - Engelm. 2007. 54 f. Dissertação (Mestrado em Engenharia Florestal) Universidade Federal de Santa Maria. Santa Maria, 2007.

BOTELHO, S. A. Princípios e métodos silviculturais. Lavras: FAEPE, 2003. 151 p.

CARneiro, J. G. A. Produção e controle de qualidade de mudas florestais. Curitiba: UFPR/ FUPEF, 1995. $451 \mathrm{p}$.

CRUZ, C. A. F.; PAIVA, H. N.; GUERRERO, C. R. A. Efeito da adubação nitrogenada na produção de mudas de sete-cascas (Samanea inopinata (Harms) Ducke). Revista Árvore, Viçosa, v. 30, n. 4, 2006. DIESEL, R.; MIRANDA, C. R.; PERDOMO, C. C. Coletânea de tecnologias sobre dejetos de suínos. Concórdia, SC: EMBRAPA - CNPSA/EMATERRS, 2002. 31 p. (Boletim informativo, 14)

EMBRAPA FLORESTA. Produção de mudas de eucalipto. Disponível em: <www.cnpf.embrapa.br/ publica/publica.htm>. Acesso em: 20 outubro/2009. EMBRAPA. Manual de métodos de análise de solo. 2. ed. Rio de Janeiro, Centro Nacional de Pesquisa de Solos, 1997. 212 p.

FONSECA, E. P. Padrão de qualidade de mudas de Trema micrantha (L.) Blume., Cedrela fissilis Vell. E Aspidosperma polyneuron Müll. Arg. produzidas sob diferentes períodos de sombreamento. 2000. $113 \mathrm{f}$. Tese (Doutorado em Agronomia) - Universidade Estadual Paulista. Jaboticabal, 2000.

GOMES, J. M. Parâmetros morfológicos na avaliação da qualidade de mudas de Eucalyptus grandis, produzidas em diferentes tamanhos de 
tubete e de dosagens de N-P-K. 2001. $126 \mathrm{f}$. Tese (Doutorado em Ciência Florestal) - Universidade Federal de Viçosa. Viçosa, 2001.

GONÇALVES, J. L. M.; POGGIANI, F. Substratos para produção de mudas florestais. In: CONGRESSO LATINO AMERICANO DE CIÊNCIA DO SOLO, 13., 1996, Águas de Lindóia. Anais... Águas de Lindóia: USP/ESALQ/SBCS/ CEA/SLACS/SBM, 1996. 1 CD ROM.

GRUBER, Y. B. G. Otimização da lâmina de irrigação na produção de mudas clonais de eucalipto (Eucalyptus urophylla $\mathrm{x}$ Eucalyptus urophylla var. plathyphylla). 2006. $145 \mathrm{f}$. Universidade de São Paulo - Escola Superior de Agricultura "Luiz de Queiroz". São Paulo, 2006. GUERREIRO, C. A.; COLLI JÚNIOR, G. Controle de qualidade de mudas de Eucalyptus spp. na Champion Papel e Celulose S. A. In: SIMPÓSIO INTERNACIONAL DE MÉTODOS DE PRODUÇÃO E CONTROLE DE QUALIDADE DE SEMENTES E MUDAS FLORESTAIS, 1984, Curitiba. Anais... Curitiba: UFPR/FUPEF. 1984, p. 127-133.

KOZLOWSKI, T. T.; KRAMER, P. J., PALLARDY, S. G. The physiological ecology of woody plants. New York: Academic Press, 1991. 657 p.

LOPES, J. L. W. Qualidade de mudas clonais do híbrido de Eucalyptus grandis vs. Eucalyptus urophylla, submetidas a diferentes regimes hídricos. 2008. 171 f. Tese (Doutorado em Agronomia) - Universidade Estadual Paulista "Júlio de Mesquita Filho" - Faculdade de Ciências Agronômicas. Botucatu, 2008.

LOPES, J. L. W.; GUERRINI, I. A.; SAAD, J. C.
C. Qualidade de mudas de eucalipto produzidas sob diferentes lâminas de irrigação e dois tipos de substrato. Revista Árvore, Viçosa, v. 31, n. 5, p. 835-843, 2007.

MAEDA, S. et al. Resíduos Industriais e Dejetos da Caprinocultura como Componentes de Substratos para Produção de Mudas de Eucalyptus badjensis. Boletim de Pesquisa Florestal, Colombo, n. 53, p.3-20, 2006.

MATOS, A. T. Disposição de Águas Residuárias no Solo. Viçosa: AEAGRI, n. 38, 2007. 141 p. MINISTÉRIO DA AGRICULTURA, PECUÁRIA E ABASTECIMENTO (MAPA), Instrução Normativa SDA $\mathrm{N}^{\circ}$ 17. Diário Oficial da União- Seção 1, no 99, 24 de maio de 2007. Métodos Analíticos Oficiais para Análise de Substratos para Plantas e Condicionadores de Solo. Brasília, 2007.

MORA, A. L.; GARCIA, C. H. A cultura do eucalipto no Brasil. São Paulo: Sociedade Brasileira de Silvicultura, 2000. 112p.

PELISSARI, R. A. Z. et al. Lodo Têxtil e água residuária da suinocultura na produção de mudas de Eucalyptus grandis. (W, Hill ex Maiden). Revista Engenharia Agrícola, Jaboticabal, v. 29, n. 2, p. 288-300, 2009.

REZENDE, A. A. P. Fertirrigação do eucalipto com efluente tratado de fábrica de celulose Kraft branqueada. 2003. 161 p. Tese (Doutorado em Engenharia Agrícola) - Universidade Federal de Viçosa. Viçosa, 2003.

SAEG. Sistema para Análises Estatísticas, Versão 9.1: Fundação Arthur Bernardes - UFV - Viçosa, 2007. 